\title{
X-ray Scattering and Chemometrics as Tools to Assist in the Identification of Gunshot Residues by Wavelength Dispersive X-ray Fluorescence Spectrometry
}

\author{
Fernanda B. Madeira, ${ }^{a}$ Victor G. P. Saide, ${ }^{a}$ Martha T. P. O. Castro, ${ }^{a}$ Cristina M. Barra,${ }^{a}$ \\ Sheisi F. L. S. Rocha, ${ }^{a}$ Vanessa G. K. Almeida, ${ }^{a}$ André V. S. Canuto, ${ }^{b}$ Gustavo G. Shimamoto, ${ }^{c}$ \\ Matthieu Tubino ${ }^{\circledR *, c}$ and José G. Rocha Jr. ${ }^{\circledR a}$ \\ anstituto de Química, Universidade Federal Rural do Rio de Janeiro, \\ BR 465, km 07, 23890-000 Seropédica-RJ, Brazil \\ ${ }^{b}$ Departamento de Homicídio, Polícia Civil do Estado do Rio de Janeiro, \\ Rua General Ivan Raposo, 500, 22621-040 Rio de Janeiro-RJ, Brazil \\ 'Instituto de Química, Universidade Estadual de Campinas, \\ P.O. Box 6154, 13083-970 Campinas-SP, Brazil
}

\begin{abstract}
Wavelength dispersion X-ray fluorescence spectrometry (WDXRF) is a non-destructive technique and therefore attractive for gunshot residues (GSR) analysis. It is well known for determination of inorganic constituents of samples. However, X-ray scattering region spectral data is not commonly used, although it may provide information about organic constituents and their interactions. This work employed $\mathrm{X}$-ray scattering region and inorganic elements spectral data for a better characterization of GSR. Swabs containing residues collected from the hand of people who fired (shooters group) and also from the hands of people which did not fire (control group) with guns were analyzed directly by the WDXRF. Brake pad and people who perform activities that favor the accumulation of characteristic elements of GSR on their hands were chosen to compose the control group. Principal components analysis (PCA) discriminated the GSR according to the firearm/cartridge used. However, similar GSR clustering did not occur without X-ray scatter data, showing the importance of X-ray scattering spectrum for GSR evaluation. The k-nearest neighbors (k-NN) method correctly classified all samples from shooters and control groups, employing from 1 to 5 nearest neighbors. No anomalous behavior was detected by PCA and hierarchical cluster analysis (HCA).
\end{abstract}

Keywords: WDXRF, GSR, HCA, PCA, k-NN

\section{Introduction}

Firearms shots leave residues at the crime scene, on the body and clothes of the shooter and on the people close to the shooting site. Therefore, the identification of gunshot residues (GSR) provides valuable information for police expertise in investigating crimes committed with the use of firearms. The GSR are mainly composed of particles from the propulsive charge, the primer, the bullet, the cartridge case and the firearm itself., ${ }^{1,2}$

Forensic expertise employs scanning electron microscopy coupled with energy dispersive X-ray spectrometry (SEM-EDX) to assess the chemical content and morphology of the particles to identify the

*e-mail: tubino@unicamp.br
GSR. Although SEM-EDX is the only technique for the identification of GSR recommended as a standard method, ${ }^{3}$ a wide variety of analytical techniques has been reported to assist the identification of GSR in forensic investigations. Such techniques are based on the detection of organic and inorganic compounds that constitute the particles.

There is a great diversity of organic compounds that may be present in the GSR such as 2,4,6-trinitrotoluene, akaridte II, diazodinitrophenol, sodium alginate, nitrocellulose, nitroguanidine, methyl centralite and others, totalizing 136 compounds. ${ }^{4-6}$ Among the main analytical methods used for the identification and quantification of organic compounds in the GSR, it is possible to cite: gas chromatography coupled to a mass spectrometer (GC-MS), ${ }^{7-9}$ high performance liquid chromatography (HPLC), ${ }^{9}$ liquid chromatography tandem- 
mass spectrometry (LC-MS/MS),${ }^{10}$ micellar electrokinetic chromatography (MEC) and attenuated total reflectance Fourier transform infrared spectroscopy (ATR-FTIR). ${ }^{11,12}$

Some metals have been preferentially investigated in the characterization of GSR by SEM-EDX spectrometry. Due the use of lead styphnate, barium nitrate and antimony sulfide in the manufacture of primers, a particle is considered characteristic to GSR if it simultaneously containing lead, antimony, and barium ${ }^{1,13}$ or consistent with GSR if containing one or two of these elements. ${ }^{3}$ However, $\mathrm{Pb}$-free cartridges or without those three elements such as S\&B Nontox, MagTech "Clean Range", Winchester Western Super-X, among others can be found on the market and their use can make difficult the identification of GSR ${ }^{14}$

Among the techniques that has been employed to assist in the identification GSR by presence of inorganic constituents the inductively coupled plasma atomic emission spectrometry (ICP OES), ${ }^{15}$ inductively coupled plasma mass spectrometry (ICP-MS), ${ }^{16}$ scanning laser ablation and inductively coupled plasma-mass spectrometry (SLA-ICP-MS), ${ }^{17}$ atomic absorption spectrometry $(\mathrm{AAS})^{18}$ and neutron activation analysis (NAA) ${ }^{19}$ can be cited. However, ICP and AAS techniques are destructive, while NAA requires a long time to complete the analysis and needs large investment in installation, maintenance and radiological safety.

The search for non-destructive methods to obtain physical or chemical information related to the organic and inorganic compounds present in the residue samples is of great relevance for forensic purposes. These methods preserve the evidence of the crime, make it possible to obtain counter-evidence and analyze the same residues by other techniques. In addition, they provide a nearly complete characterization of the residues, making them less dependent on the presence of some specific compound or element.

For this purpose, emphasis has recently been given to the use of Raman spectroscopy. ${ }^{17,20,21}$

Bueno et al. ${ }^{21}$ used the near-infrared Raman microspectroscopy for the analysis of organic and inorganic compounds to differentiate GSR particles. The authors employed principal component analysis (PCA), k-nearest neighbor (k-NN), partial least-squares discriminant analysis (PLSDA), and support vector machines discriminant analysis (SVMDA) for statistical evaluation of data. The residues were collected on lint cloth wipes used as a target and placed in front (at $0.3 \mathrm{~m}$ ) of the barrel of the firearm. It was only necessary to transfer the GSR to an aluminum slide to perform the analysis. According to the authors, a larger number of samples is needed to consider their study conclusive.
Raman spectroscopy was used by López-López et al. ${ }^{20}$ for the analysis of GSR produced by different types of cartridge, with a focus on its organic components. The spectral data of GSR showed similarity to the data produced by the unfired gunpowder cartridges. Karahacane et al. ${ }^{22}$ used Raman spectrometry to study organic GSR produced by rifles of different calibers. Principal components (PC) and support vector machine (SVM) methods applied to the spectral data differentiated the samples according to the calibers. The authors associated the differentiation with the presence of diphenylamine and ethyl centralite used as stabilizers.

The X-ray fluorescence spectrometry (XRF) is used to identify and quantify inorganic species in different samples. Little or no prior sample preparation is required when using this technique. The speed of analysis and the fact that this technique is non-destructive and multielementary make it promising for GSR analysis. ${ }^{23-25}$ However, as the limit of detection of this technique is relatively high, the identification of some elements in this matrix can be seriously compromised.

Lisboa et al..$^{25}$ employed X-ray energy dispersive fluorescence (EDXRF) technique for GSR analysis collected from shooters hands with swabs moistened with ethylenediamine tetraacetic acid (EDTA) solution. The detection of the characteristic elements of the GSR ( $\mathrm{Pb}, \mathrm{Ba}$ and $\mathrm{Sb}$ ) was achieved due to the large number of shots fired (ten shots) and by the type of weapon used. Consequently, a large amount of residue must have been deposited on the hands of the shooter. It is interesting to use techniques with fewer shots for forensic purposes.

Ferreira et al. ${ }^{26}$ identified and discriminated GSR from different ammunitions by total reflection $\mathrm{X}$-ray fluorescence (TXRF) and PCA. The GSR samples were collected from hands of shooters employing swabs and the residues were analyzed after extraction with $5 \% \mathrm{v} / \mathrm{v}$ nitric acid. According to the authors, the method was suitable for the identification of inorganic components from 1- and 3 -shot residues of some types of ammunition investigated. Sample discrimination as a function of the conventional ammunition calibers was feasible. Sarapura et al. ${ }^{27}$ also used TXRF for the GSR analysis. However, the analysis was focused on the relationship of three elements present in GSR ( $\mathrm{Pb}, \mathrm{Ba}$ and $\mathrm{Sb}$ ). Pistols from different manufacturers were used with $9 \mathrm{~mm}$ cartridges. SVMDA and PLSDA enabled the correct classification of all samples analyzed.

The XRF data has information about organic compounds implicit in its spectrum in the scattering region. Chemometrics makes it possible to explore this information. ${ }^{28}$ Thus, the XRF became a valuable tool for 
GSR analysis because it would bring spectral information related to organic and inorganic species. However, the literature does not report, to our knowledge, the use of this region of the spectrum for this purpose.

This work shows that the combination of the X-ray scattering data with the spectral data of inorganic elements, obtained by wavelength dispersion X-ray fluorescence spectrometry (WDXRF), can contribute to the identification and classification of the GSR if these data are processed with suitable chemometrics techniques. For such, residues collected from the hands of people who carried out two and three shots with firearms (shooters group) and from who had not contact with firearms (control group) were analyzed to identify whether the residue present on the hands of suspected shooters contains the GSR and, if so, which firearm/cartridge is used for firing.

Those who perform daily work activities such as mechanics, painters, electricians and gas station attendants were considered as the control group, since they are in contact with the elements present in the GSR, especially $\mathrm{Pb}$, $\mathrm{Ba}$ and $\mathrm{Sb}^{29}$ The use of this control group aimed to evaluate the probable existence of some risk in creating wrong associations, which would result in the condemnation of these people. A sample of brake pad was also analyzed.

\section{Experimental}

\section{Residues collection}

The GSR samples were collected at the Division of Guard and Surveillance of the Federal Rural University of Rio de Janeiro and at the School of Specialized Instruction (EsIe) of the Ministry of the Army-Brazil. Four types of GSR were obtained from three different firearms and from four cartridges of different sizes and capsule materials, according specifications listed in Table 1. The shots were carried out by four shooters, so-called A, B, C and D. They had their hands washed with detergent, distilled water and Mili-Q ${ }^{\circledR}$ water prior to each firing sequence. For each cartridge type, four GSR samples from three shots and two GSR samples from two shots were obtained, totalizing 24 samples (called shooters group). In collecting the residues

Table 1. Specifications of firearms and cartridges used in shots and identification codes of gunshot residues (GSR) samples

\begin{tabular}{|c|c|c|c|c|c|}
\hline GSR type & Code & Firearm specification & Cartridge specification & Shooter & Number of shoots \\
\hline \multirow{6}{*}{ I } & $\operatorname{Re} 1$ & \multirow{6}{*}{$\begin{array}{c}\text { revolver Taurus .38 Special } \\
\text { MK } 862421\end{array}$} & \multirow{6}{*}{$\begin{array}{l}\text { Winchester } .38 \text { SPL hollow } \\
\text { point silvertip } 110 \text { grain }\end{array}$} & B & 3 \\
\hline & $\operatorname{Re} 2$ & & & A & 3 \\
\hline & $\operatorname{Re} 3$ & & & $\mathrm{~B}$ & 3 \\
\hline & $\operatorname{Re} 4$ & & & A & 3 \\
\hline & $\operatorname{Re} 5$ & & & $\mathrm{~B}$ & 2 \\
\hline & $\operatorname{Re} 6$ & & & A & 2 \\
\hline \multirow{6}{*}{ II } & Rv1 & \multirow{6}{*}{$\begin{array}{c}\text { revolver Taurus .38 Special } \\
\text { MK } 862421\end{array}$} & \multirow{6}{*}{$\begin{array}{l}\mathrm{CBC} .38 \mathrm{SPL}+\mathrm{P}+\text { hollow } \\
\text { point gold } 125 \text { grain }\end{array}$} & A & 3 \\
\hline & Rv2 & & & $\mathrm{B}$ & 3 \\
\hline & Rv3 & & & A & 3 \\
\hline & Rv4 & & & B & 3 \\
\hline & Rv5 & & & A & 2 \\
\hline & Rv6 & & & $\mathrm{B}$ & 2 \\
\hline \multirow{6}{*}{ III } & $\mathrm{P} 1$ & \multirow{6}{*}{$\begin{array}{l}\text { pistol IMBEL } 9 \\
\text { M973 } 11323\end{array}$} & \multirow{6}{*}{$\begin{array}{c}9 \mathrm{~mm} \text { luger speer lawman } \\
124 \text { grain }\end{array}$} & $\mathrm{C}$ & 3 \\
\hline & $\mathrm{P} 2$ & & & $\mathrm{C}$ & 3 \\
\hline & $\mathrm{P} 3$ & & & $\mathrm{C}$ & 3 \\
\hline & $\mathrm{P} 4$ & & & $\mathrm{C}$ & 3 \\
\hline & P5 & & & $\mathrm{C}$ & 2 \\
\hline & P6 & & & $\mathrm{C}$ & 2 \\
\hline \multirow{6}{*}{ IV } & F1 & \multirow{6}{*}{$\begin{array}{l}\text { riffle FN FAL } \\
\text { M964 } 100167\end{array}$} & \multirow{6}{*}{$\begin{array}{c}.308 \text { Win } 148 \text { grain German } \\
\text { military surplus ammo }\end{array}$} & $\mathrm{D}$ & 3 \\
\hline & $\mathrm{F} 2$ & & & $\mathrm{D}$ & 3 \\
\hline & F3 & & & $\mathrm{D}$ & 3 \\
\hline & F4 & & & $\mathrm{D}$ & 3 \\
\hline & F5 & & & $\mathrm{D}$ & 2 \\
\hline & F6 & & & $\mathrm{D}$ & 2 \\
\hline
\end{tabular}

SPL: Super Police; CBC: Companhia Brasileira de Cartuchos; IMBEL: Indústria de Materiais Bélicos do Brasil; FAL: Fuzil Automático Leve. 
resulting from the firing with the revolver, an alternation of the shooters was made, as listed in Table 1.

The GSR were collected in the pincer-dorsal region of the hand using swabs soaked with $2 \% \mathrm{~m} / \mathrm{v}$ ultra-pure EDTA aqueous solution, employing the smear technique and keeping the collecting surface in contact with the shooter's hand for about $30 \mathrm{~s}$, according to the methodology used by Reis et al. ${ }^{30}$ Swabs containing the GSR were stored in $2 \mathrm{~mL}$ polypropylene Eppendorf tubes. The tubes were not completely sealed so that the solvent could evaporate at room temperature.

Samples of residues in the hands of people that did not shoot (control group) were collected using the same technique employed in the cases of shooters. These people were car mechanics, truck mechanics, automotive painters, electricians and gas station attendants (Table 2) in the exercise of their profession. This collection was also performed on the surface of a brake pad sample by rubbing a cotton swab dipped in EDTA solution, because it was reported that this material also contains GSR characteristic elements $(\mathrm{Pb}, \mathrm{Ba}$ and $\mathrm{Sb}){ }^{31,32}$ This sample was inserted in the control group.

Table 2. Codes used for the identification of control group sample

\begin{tabular}{lc}
\hline Code & Occupation \\
\hline G1 & attendant of the gas station 1 \\
G2 & attendant of the gas station 2 \\
E1 & electrician \\
Pi1 & painter 1 \\
Pi2 & painter 2 \\
M1 & mechanic 1 \\
M2 & mechanic 2 \\
M3 & mechanic 3 \\
Tm1 & truck mechanic 1 \\
Tm2 & truck mechanic 2 \\
BP & brake pad \\
\hline
\end{tabular}

aThis professional was performing the exchange of brake pads immediately prior to the residue collection.

\section{X-ray fluorescence analysis}

The analyses were performed on a sequential wavelength dispersion X-ray fluorescence spectrometer (WDXRF, Shimadzu, model XRF-1800, Kyoto, Japan), 4 kW X-ray, pendulum-type sample loading system and rhodium target $\mathrm{X}$-ray tube. Samples were not subjected to any pretreatment before being analyzed and were dry at the time of analysis. The swab cotton was removed using plastic tweezers and placed inside the sample holder, covered with Mylar ${ }^{\circledR}$ thin- film, thickness $2.5 \mu \mathrm{m}$ (Chemplex, 100) and inserted into the equipment. An area of the swab cotton corresponding to a $1 \mathrm{~cm}$ diameter circle was irradiated. The spectra were obtained using all angles that could be selected by the goniometer using the $\mathrm{LiF}, \mathrm{Ge}$, TAP (thallium acid phthalate) and PET (pentaerythriol) crystals to obtain data referring to a greater range of elements. The measurement time for each sample was $20 \mathrm{~min}$. In order to eliminate the effects of the matrix, cellulose was discarded by the software in the spectra obtained during the scanning.

\section{Chemometric analysis}

The chemometrics methods used for data analysis were PCA and hierarchical cluster analysis (HCA) from Unscrambler $\mathrm{X}^{\circledR} 9.1^{33}$ and k-NN from Statistica ${ }^{\mathrm{TM}} 13.2 .^{34}$ The spectral ranges presented in Table 3 were selected for chemometric analysis. These ranges encompass the X-ray scattering region (organic compounds) and the region of the inorganic elements.

Table 3. Spectral bands selected for chemometrics methods and observable elements with the different crystals in the WDXRF analysis

\begin{tabular}{lcc}
\hline $\begin{array}{l}\text { Spectral band }(2 \theta) / \\
\text { degree }\end{array}$ & Crystal & Element \\
\hline $15-20$ & $\mathrm{LiF}(220)$ & $\mathrm{Ti}-\mathrm{U}$ \\
$97-140$ & $\mathrm{LiF}(220)$ & $\mathrm{K}, \mathrm{Ca}, \mathrm{Sn}-\mathrm{Cs}$ \\
$53-57$ & $\mathrm{TAP}$ & $\mathrm{Na}$ \\
$91-95$ & $\mathrm{Ge}$ & $\mathrm{Cl}$ \\
$142.1-148$ & $\mathrm{PET}$ & $\mathrm{Al}$ \\
$138-144$ & $\mathrm{Ge}$ & $\mathrm{P}$ \\
$108-114$ & $\mathrm{Ge}$ & $\mathrm{S}$ \\
$43-47$ & $\mathrm{TAP}$ & $\mathrm{Mg}$ \\
$106-112$ & $\mathrm{PET}$ & $\mathrm{Si}$ \\
\hline
\end{tabular}

TAP: thallium acid phthalate; PET: pentaerythriol.

One spectral data matrix $(35 \times 706)$ was constructed in such a way that each row corresponded to the spectrum of a sample and each column to the angle (degree) of the spectral data. For the discrimination of GSR type, spectral data were mean-centered followed by variance scaling and PCA was performed.

The samples of shooters and control groups were classified by k-NN method and atypical behavior was investigated by PCA and HCA. For this, spectral data were transformed and preprocessed by: (i) smoothed moving average with seven segments; (ii) baseline correction; (iii) quantile normalization and (iv) autoscaling. The HCA, PCA and k-NN analysis were performed using the Ward method, the singular value decomposition (SVD) 
algorithm and Euclidean distance, respectively. Selection of the optimal number of nearest neighbors (k) was based on the accuracy in cross-validation performed with v-value and seed equals to 10 and 1000 , respectively. The samples were randomly distributed by Statistica ${ }^{34}$ software into the training (70\%) and test (30\%) sets.

\section{Results and Discussion}

The analysis of XRF spectrum revealed the presence of characteristic signals of some GSR constituents, such as sulfur, phosphor, silicon, sodium, potassium, iron, calcium, aluminum, chromium, nickel and chloride. All these elements have been previously reported as inorganic compounds that may contribute to gunshot residue. .,13,16,17 $^{-1}$

Signals of $\mathrm{Pb}, \mathrm{Ba}$ and $\mathrm{Sb}$ have not been observed in XRF spectrum. However, the X-ray scattering region of the fluorescence spectrum (Figure 1) can provide additional information on the analyzed residues. The scattering profile is affected by organic compounds contained in the GSR. Furthermore, as the EDTA present in the swabs can produce complexes with the metal elements of the GSR, even if they are in low concentrations, different scattering profiles are generated. Thus, the inorganic elements not detected at characteristic angles can influence the scattering region, bringing information about them.

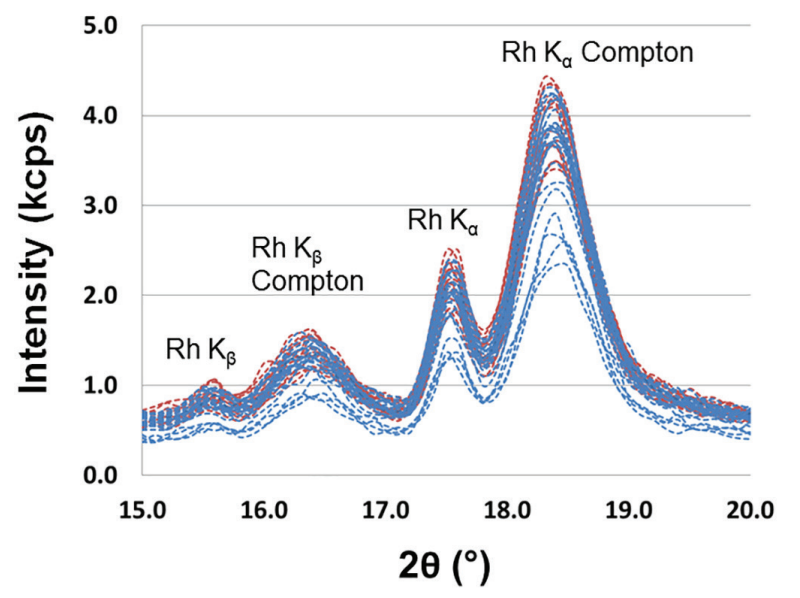

Control group

Shooters group

Figure 1. Scattering region of the superimposed spectra of the residue samples collected from shooters and control groups.

\section{Identification of the GSR type by PCA}

In the spectral data of GSR from 3-shot, the PCA shows that the $\mathrm{PC} 1$ and $\mathrm{PC} 3$ provide discriminatory information for the identification of the origin of GSR (firearm/ cartridge). PC1 and PC3 describes 14\% and PC3 9\% of the total variation, respectively. The Figure 2 a shows that the PCA has discriminatory capacity for the four types of GSR tested, and there are no anomalous samples for this model within a $95 \%$ confidence interval, according to Hotelling's $\mathrm{T}^{2}$ ellipse. The analysis of loading graphs (Figure $2 b$ ) revealed that chloride spectral data promote positive PC3 values, contributing to the discrimination of GSR type III. The XRF spectrum gave characteristic chloride signals only in GSR type III (P1 to P6). The scattering region also promotes positive PC3 values and thus contributes to separate GSR type III. In addition, the scattering region had a relatively high influence on PC1 positive values, contributing to the discrimination between GSR type I and GSR type IV. The absence of phosphorus spectral data in the third quadrant indicates that this element separates GSR of type I, II and III from GSR of type IV.

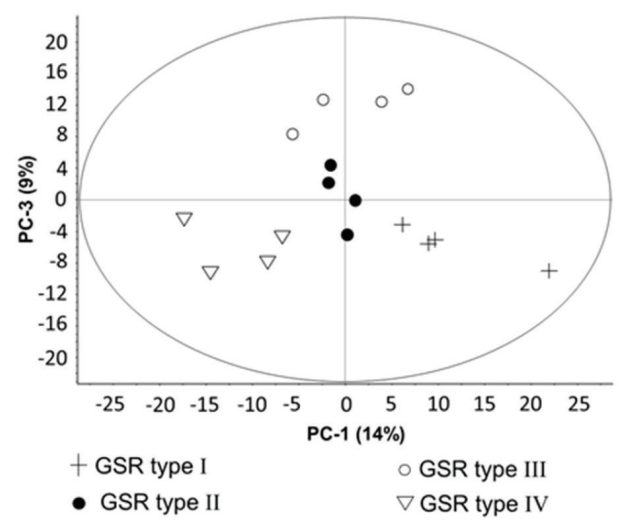

(a)

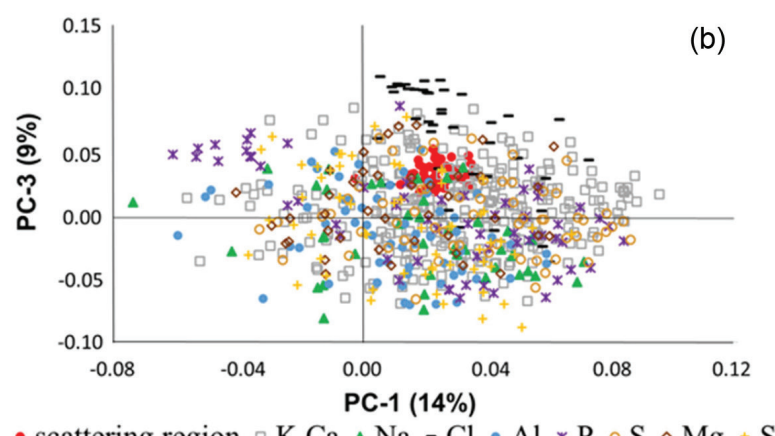

- scattering region $\square \mathrm{K}, \mathrm{Ca} \triangle \mathrm{Na}-\mathrm{Cl} \bullet \mathrm{Al} \times \mathrm{P} \circ \mathrm{S} \bullet \mathrm{Mg}+\mathrm{Si}$

Figure 2. (a) $\mathrm{PC} 1 \times \mathrm{PC} 3$ scores plot of 3 -shot GSR samples with Hotelling $\mathrm{T}^{2}$ ellipse after spectra processing by PCA and (b) loading graphs. Each symbol in (b) refers to a spectral band shown in Table 3.

The 2 and 3-shot GSR sample data sets were processed by PCA to assess whether the number of shots could affect the results. The obtained scores plot (Figure 3a) shows that the 2 and 3-shot GSR samples were not well grouped for the same GSR type, however they are close to each other. Collecting sample after 3 shots obviously decreases the random margin of error with respect to the collection after 2 shots, as the former have a greater amount of GSR adsorbed on the cotton. Thus, greater uniformity 
in the 3-shot GSR samples was sufficient for a clearer classification of samples per GSR type. The analysis of loading graphs (Figure $3 b$ ) shows that the variables had a similar effect on the discrimination of the GSR type shown in Figure 2b, except that PC1 has been replaced by PC2.

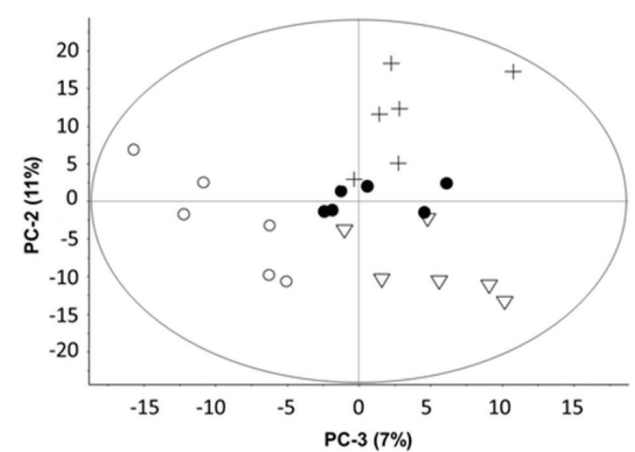

(a)

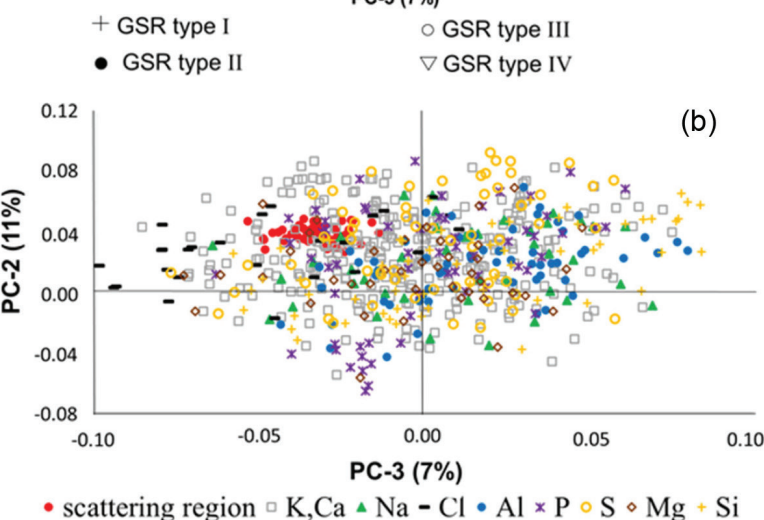

Figure 3. (a) $\mathrm{PC} 2 \times \mathrm{PC} 3$ scores plot for 2 and 3 -shot GSR samples with Hotelling $\mathrm{T}^{2}$ ellipse after spectra processing by PCA and (b) loading graphs. Each symbol in (b) refers to a spectral band shown in Table 3.

It was not observed the grouping of GSR samples of the same type in the scores plot when PC1 was used in the analysis of the samples of 2 and 3 -shots. However, in Figure 2a, which contains only the 3 -shot samples, PC1 contributed to the grouping. $\mathrm{PC} 1$ is probably affected by the amount of GSR collected after firing. However, PC1 makes no distinction between two and three shots samples, as the amount of GSR deposited on the hand must vary for the same number of shots. The amount of GSR deposited after two shots should vary more as less GSR was released into the atmosphere. With three shots, the amount of GSR deposited in the hands must be greater and the amount collected must vary less between samples, producing a better grouping of samples (Figure 2a).

Shooters A and B participated in both shots for obtaining GSR type I and II (Table 1). Nevertheless, these GSR were discriminated without the influence of these shooters, indicating that the grouping of samples by the PCA may be affected by the characteristics of the GSR, without the influence of the person who made the shot.
Otherwise, shooters A and B should form distinct groups in Figure 2a, fact which was not observed.

Despite the care taken to ensure that spectral variations occur exclusively by the presence of GSR (or not) or differences in the GSR type, the X-ray fluorescence spectrum profile could be influenced by several factors such as: (i) different amounts of fragments from skin, fat and other organic compounds removed by the smear technique from the people hands; (ii) different amounts of EDTA solution absorbed by swabs; (iii) different cotton masses that make up the swabs; (iv) different amounts of residue deposited in the collection regions, which are strongly influenced by external factors such as atmospheric humidity, air current, shooting angle, etc. However, the proposed method was able to promote the grouping of the same GSR type, despite the mentioned sources of variability. Thus, the technique could be considered adequate for GSR analysis and could be applied to real casework.

The PCA did not promote separation of sample groups according to GSR type when the scattering band (Ti-U) was discarded. This demonstrates the relevance of using this region of the spectrum for the characterization of GSR types. Thus, for good discrimination with this proposed methodology it is necessary to take into account the two spectral regions since both organic and inorganics compounds are important for the samples clustering.

\section{k-NN method for shooters and control groups classification}

The samples for the test set (Rv2, Rv3, Rv4, Re1, Re4, F1, G1, Bp, El and M3) and the training set (with remaining samples) were randomly chosen by Statistica ${ }^{\mathrm{TM}}$ software. $^{34}$ The analysis of cross-validation accuracy revealed that a good prediction can be performed employing up to 5 nearest neighbors $(\mathrm{k} \leq 5)$ (Figure 4). All samples of test set were correctly classified with k-NN method employing from 1 to 5 nearest neighbors (Table 4).

Although it is not commonly recommended to use

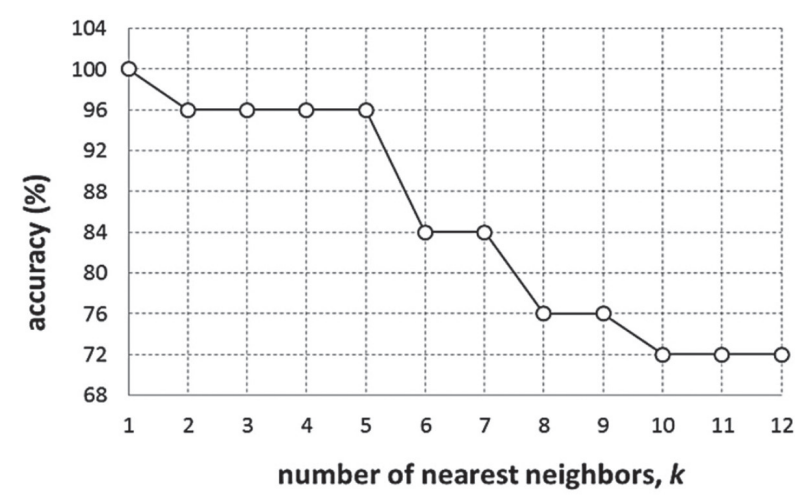

Figure 4. Number of nearest neighbors versus cross-validation accuracy for optimal $\mathrm{k}$ selection. 
Table 4. Classification obtained with the k-NN method employing $\mathrm{k}=1$ to 5

\begin{tabular}{lcc}
\hline Category & Number of samples & $\begin{array}{c}\text { Samples incorrectly } \\
\text { classified }\end{array}$ \\
\hline Shooters group & 6 & 0 \\
Control group & 4 & 0 \\
Total & 10 & 0 \\
\hline Percentage of correct classification / \% & 100 \\
\hline
\end{tabular}

only 1 nearest neighbor to classify samples when the classes used have different sizes, ${ }^{35}$ as in this work, $\mathrm{k}=1$ gave greater accuracy in cross-validation (Figure 4) and provided the correct classification of all samples. However, values of $\mathrm{k}$ within the range $2 \leq \mathrm{k} \leq 5$ could be used for classification, as the use of up to 5 nearest neighbors did not affect the classification of samples relative to $\mathrm{k}=1$.

Since k-NN does not detect samples with atypical behavior, ${ }^{35} \mathrm{PCA}$ and HCA were used as parallel techniques to verify the general behavior of the samples and to detect if there were different trends in some samples.

PCA processing differentiated the shooters group from the control group (Figure 5a). PC1 and PC2 described 45 and $9 \%$ of the total variation of data set, respectively. Some samples from control group (M1, M2 and M3) were outside the $95 \%$ confidence interval. Figure 5a shows that the samples collected from the shooters predominate on the right, with $\mathrm{PC} 1$ being responsible for discrimination. The loading graphs (Figure 5b) revealed that spectral data of
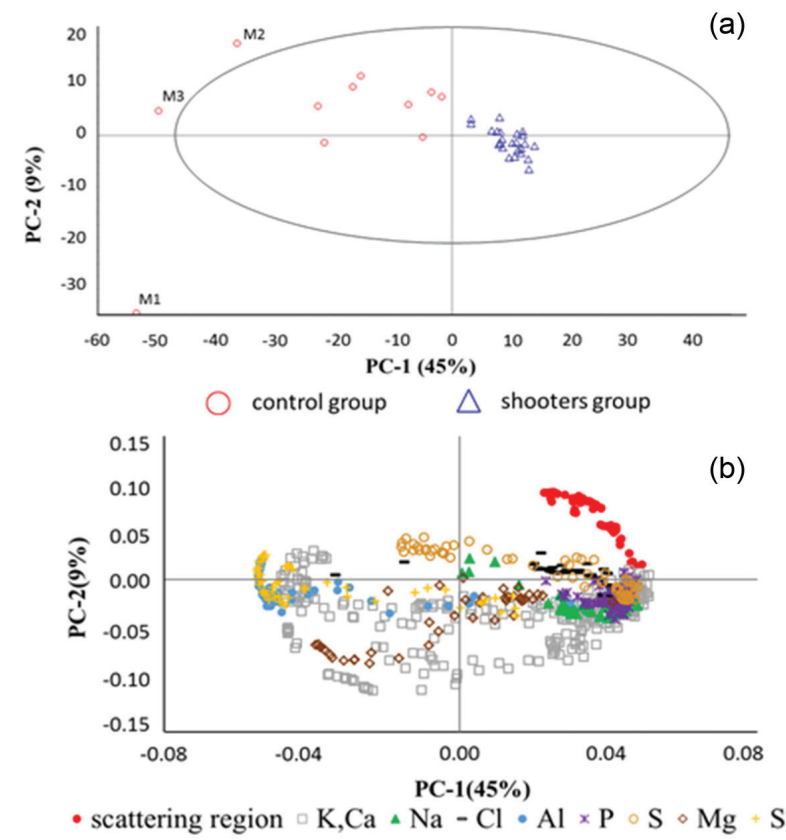

Figure 5. (a) $\mathrm{PC} 1 \times \mathrm{PC} 2$ scores plot of shooters and control group samples after spectra processing by PCA with Hotelling $\mathrm{T}^{2}$ ellipse and (b) loading graphs. Each symbol in (b) refers to a spectral band shown in Table 3. sodium, chloride, phosphorus and scattering region promote positive PC1 values, contributing to the discrimination of shooters group.

The dendrogram obtained by HCA (Figure 6) also discriminated the shooters group (group 2) and control group with relative distance equal to 6.3. However, M1, M2, M3 and Bp samples formed a distinct group (group 1) from the other control group samples (Pi, Tm1, Tm2, El, G1 and G2), which formed the group 3. The formation of group 1 was due to the fact that samples M1, M2 and M3 were collected from professionals who perform the same work activity (car mechanic). The professional related to the M3 sample, when asked, performed a change of brake pads on the day of collection. This explains the presence of Bp sample group 1.

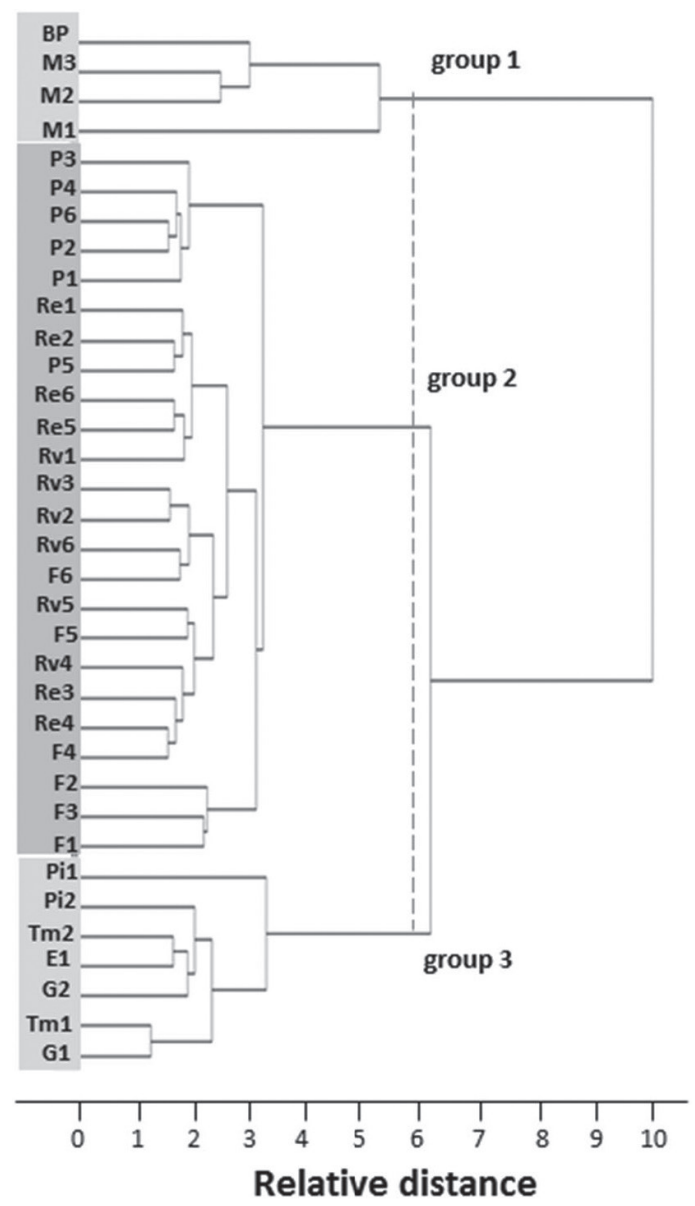

Figure 6. Dendrogram obtained from HCA by the Ward method with the formation of 3 groups.

The occurrence of outliers in PCA (Figure 5a) and formation of more than one control group in HCA (Figure 6) are expected, since there is a great variability in the composition of the sample collected from the control group due to the diversity of residues present on the hands of the components of this group, referring to the different 
work environments. However, Figures 5a and 6 clearly show that samples from the control group differ from samples taken from shooters' hands, contributing for the excellent classification performed by the k-NN method (Table 4).

The choice of the professionals (and brake pad) that make up the control group was motivated by reports that their work activities favor the accumulation of GSR characteristic elements, especially $\mathrm{Pb}, \mathrm{Ba}$ and $\mathrm{Sb}^{30,31} \mathrm{The}$ correct classification of the samples collected from these professionals and people who fired with guns shows that the k-NN method, in parallel with PCA and HCA, is a valuable tool for forensic purposes.

The correct classification of the samples of the test set by the k-NN method was possible, although no signals of $\mathrm{Pb}, \mathrm{Ba}$ and $\mathrm{Sb}$ were observed in XRF spectrum obtained by the WDXRF technique. This suggests that the classification may be linked to an independent sample composition of these characteristic elements, opening perspectives for the use of these techniques in GSR analysis without these elements.

\section{Conclusions}

The use of the WDXRF technique and spectral data of $\mathrm{X}$-ray scattering region were used for the first time in this work for the analysis of GSR. WDXRF proved to be adequate for contributing to the identification of the firearms/cartridges from the GSR analysis collected from the hands of shooters. However, this was only possible when the spectral data obtained in the characteristic regions of the inorganic elements are processed by the PCA together with the X-ray scattering region (with rhodium source). The clustering in PCA was slightly affected by the number of shots fired.

The exploratory analysis of the data through PCA and HCA discriminated the collected residues from shooters and control group hands, making them promising tools for the identification of the GSR. The k-NN method classified correctly all residues collected from the hands of control group and shooters, employing from 1 to 5 nearest neighbors. Although the methodology is promising, tests with a larger number of samples are needed to certify its effectiveness and applicability.

The new approach to the use of X-ray fluorescence presented in this paper for the identification of GSR was based on the analysis of spectral data of organic (X-ray scattering region) and inorganic constituents, which makes the proposed method suitable for the analysis of GSR, including those $\mathrm{Ba}, \mathrm{Sb}$ and $\mathrm{Pb}$ free. As it is a non-destructive method, the samples could be analyzed later by other techniques, which would lead to better characterization and preservation of evidence.

\section{Acknowledgments}

This study was financed in part by the Coordenação de Aperfeiçoamento de Pessoal de Nível Superior, Brazil (CAPES), finance code 001.

\section{Author Contributions}

This article was based on the master's thesis of the main author Fernanda B. Madeira. José G. Rocha Junior was the supervisor and Vanessa G. K. Almeida was the co-supervisor of the main author. The specification of the individual contribution of each author is: Fernanda B. Madeira (investigation and visualization); Victor G. P. Saide (formal analysis and visualization of the reviewed version); Martha T. P. O. Castro (formal analysis and visualization of the first version); Cristina M. Barra (writing original draft); Sheisi F. L. S. Rocha (writing-review and editing); Vanessa G. K. Almeida (conceptualization); André V. S. Canuto (methodology-sample collection); Gustavo G. Shimamoto (methodology-sample preparation and XRF analysis); Matthieu Tubino (funding acquisition and resources); José G. Rocha Junior (conceptualization and supervision).

\section{References}

1. Perez, J. J.; Watson, D. A.; Levis, R. J.; Anal. Chem. 2016, 88, 11390.

2. Maitre, M.; Kirkbride, K. P.; Horder, M.; Roux, C.; Beavis, A.; Forensic Sci. Int. 2017, 270, 1.

3. Brożek-Mucha, Z.; Anal. Bioanal. Chem. 2017, 409, 5803.

4. Goudsmits, E.; Sharples, G. P.; Birkett, J. W.; TrAC, Trends Anal. Chem. 2015, 74, 46.

5. Dalby, O.; Butler, D.; Birkett, J. W.; J. Forensic Sci. 2010, 55, 924.

6. Goudsmits, E.; George, P. S.; Jason, W. B.; Sci. Justice 2016, 56,421 .

7. Goudsmits, E.; Blakey, L. S.; Chana, K.; Sharples, G. P.; Birkett, J. W.; Forensic Sci. Int. 2019, 43, 76.

8. Gallidabino, M.; Romolo, F. S.; Weyermann, C.; Anal. Bioanal. Chem. 2015, 407, 7123.

9. Taudte, R. V.; Roux, C.; Blanes, L.; Horder, M.; Kirkbride, K. P.; Beavis, A.; Anal. Bioanal. Chem. 2016, 408, 2567.

10. Gassner, A. L.; Weyermann, C.; Forensic Sci. Int. 2016, 264 , 47.

11. Perre, C.; Corbin, I.; Blas, M.; McCord, B. R.; J. Chromatogr. A 2012, 1267, 259.

12. Bueno, J.; Lednev, I. K.; Anal. Chem. 2014, 86, 3389. 
13. Blakey, L. S.; Sharples, G. P.; Chana, K.; Birkett, J. W.; J. Forensic Sci. 2018, 63, 9.

14. Nunziata, F.; Def. Technol. 2019, 15, 272.

15. Santos, A.; Ramos, P.; Fernandes, L.; Magalhães, T.; Almeida, A.; Sousa, A.; Forensic Sci. Int. 2015, 247, 62.

16. Abrego, Z.; Grijalba, N.; Unceta, N.; Maguregui, M.; Sanchez, A.; Fernández-Isla, A.; Barrio, R. J.; Analyst 2014, 139, 6232.

17. Aksoy, Ç.; Bora, T.; Şenocak, N.; Aydın, F.; Forensic Sci Int. 2015, 250, 87.

18. Capannesi, G.; Ciavolal, C.; Sedda, A. F.; Forensic Sci. Int. 1993, 61, 75 .

19. Chohra, M.; Beladel, B.; Ahmed, L. B.; Mouzai, M.; Akretche, D.; Zeghdaoui, A.; Benamar, M. E. A.; J. Radiat. Res. Appl. Sci. 2015, 8, 404.

20. López-López, M.; Delgado, J. J.; García-Ruiz, C.; Anal. Chem. 2012, 84, 3581.

21. Bueno, J.; Sikirzhytski, V.; Lednev, I. K.; Anal. Chem. 2012, $84,4334$.

22. Karahacane, D. S.; Dahmani, A.; Khimeche, K.; Forensic Sci Int. 2019, 301, 129.

23. Jenkins, R.; X-Ray Fluorescence Spectrometry, $2^{\text {nd }}$ ed.; Wiley Interscience: New York, USA, 1999.

24. Romão, W.; Schwab, N. V.; Bueno, M. I.; Sparrapan, R.; Eberlin, M. N.; Martiny, A.; Sabino, B. D.; Maldaner, A. O.; Quim. Nova 2011, 34, 1717.
25. Lisboa, W. M.; Assis, J. T.; Zani, J. H.; Engevista 2017, 19, 950.

26. Ferreira, L. P.; Nascentes, C. C.; Valladão, F. N.; Lordeiro, R. A.; J. Braz. Chem. Soc. 2019, 30, 2582.

27. Sarapura, P.; Gonzalez, M. F.; Gonzalez, F.; Morzan, E.; Cerchietti, L.; Custo, G.; Appl. Radiat. Isot. 2019, 153, 108841.

28. Bueno, M. I. M. S.; Castro, M. T.; Souza, A. M.; Oliveira, E. B. S.; Teixeira, A. P.; Chemom. Intell. Lab. Syst. 2005, 78, 96.

29. Garofano, L.; Capra, M.; Ferrari, F.; Bizarro, G. P.; Di Tullio, D.; Dell'Olio, M.; Ghitti, A.; Forensic Sci. Int. 1999, 103, 1.

30. Reis, E. L. T.; Sarkis, J. E. S.; Rodrigues, C.; Neto, O. N.; Viebig, S.; Quim. Nova 2004, 27, 409.

31. Torre, C.; Mattutino, G.; Vasino, V.; Robino, C.; J Forensic Sci. 2001, 47, 494.

32. Wei, L.; Choy, Y. S.; Cheung, C. S.; Tribol. Int. 2019, 138, 99.

33. Unscrambler $X$, version 9.1; CAMO Analytics AS, Norway, 2004.

34. Statistica, 13.0; StatSoft, Tulsa, OK, USA, 2015.

35. Ferreira, M. M. C.; Quimiometria: Conceitos, Métodos e Aplicações, $1^{\text {st }}$ ed.; Editora da Unicamp: Campinas, Brazil, 2015.

Submitted: February 15, 2020

Published online: June 19, 2020 